\title{
CULTURA DA SOJA EM FUNÇÃO DA PROFUNDIDADE DE SEMEADURA E DA CARGA VERTICAL SOBRE A FILEIRA DE SEMEADURA
}

\author{
DANILO C. C. GROTTA ${ }^{1}$, CARLOS E. A. FURLANI ${ }^{2}$, ROUVERSON P. SILVA ${ }^{3}$, \\ LEONARDO DOS SANTOS ${ }^{4}$, JORGE W. CORTEZ $^{5}$, GUSTAVO N. DOS REIS ${ }^{6}$
}

\begin{abstract}
RESUMO: A análise do efeito da profundidade de semeadura e carga vertical visando a melhorar o aproveitamento, e a integração entre o solo e a cultura é muito difícil. O objetivo do presente trabalho foi avaliar cargas verticais $(0 ; 98 ; 196$ e $294 \mathrm{~N})$ sobre as rodas compactadoras das semeadoras, combinando com profundidades de semeadura $(0,03 ; 0,05$ e $0,07 \mathrm{~m})$ para a cultura da soja. O trabalho foi realizado no DER/UNESP - Jaboticabal, na pista de ensaio do Laboratório de Máquinas e Mecanização Agrícola (LAMMA), utilizando o delineamento experimental em blocos casualizados, no esquema fatorial $(4 \times 3)$, com 12 tratamentos e três repetições, totalizando 36 observações. Foram analisados: emergência de plântulas, estandes inicial e final, índice de sobrevivência, área mobilizada e rendimento de grãos. Os resultados evidenciaram que, com exceção da área mobilizada em relação à profundidade de semeadura, todas as demais variáveis não foram influenciadas pelos tratamentos.
\end{abstract}

PALAVRAS-CHAVE: estande de plantas, área mobilizada, rendimento de grãos.

\section{SOYBEAN CROP IN FUNCTION OF THE DEPTH OF SOWING AND VERTICAL LOAD ON THE ROW OF SOWING}

\begin{abstract}
The choice of a soil tillage system, aiming the best use and integration between soil and crop, is very difficult. The objective of the present work was to evaluate vertical loads $(0 ; 98$; 196 and $294 \mathrm{~N})$ on the press wheels of the seeders working at sowing depths $(0.03 ; 0.05$ and 0.07 $\mathrm{m})$ for the soybean. The work was carried out at Rural Engineering Department of UNESP - São Paulo State University, Jaboticabal, Brazil, in the Machines and Mechanization Laboratory's area. The experiment design was $4 \times 3$ factorial in randomized blocks with three replications, totalling 12 treatments and 36 observations. The emergence, initial and final population of cultivation, index of surving plants, immobilized area in sowing and the yield grain were analyzed. The results showed that, except for mobilized area concerning the working depth of sowing shaft, all the other variables were not influenced by the treatments.
\end{abstract}

KEYWORDS: stand of plants, mobilized area, grain yield.

\section{INTRODUÇÃO}

Para a implantação da cultura da soja, é de extrema importância o bom preparo do solo. Tal preparo é realizado para propiciar condições satisfatórias de semeadura, germinação, emergência das plântulas, desenvolvimento e rendimento das plantas. A compactação do solo sobre a fileira de semeadura torna-se de grande importância, pois provoca alterações em seu interior, modificando boa parte do ambiente físico sob o qual se desenvolve a cultura. Os quatro fatores físicos do solo que necessitam ser considerados quando se avaliam as respostas das culturas a um determinado tipo de preparo, são: umidade, temperatura, aeração e resistência mecânica do solo à penetração,

\footnotetext{
${ }^{1}$ Pós-graduando, Doutorado Produção Vegetal) DER/UNESP - Jaboticabal. dcgrotta@yahoo.com.br. Bolsista CNPq.

2 Prof. Adjunto, Departamento de Engenharia Rural, UNESP - Jaboticabal, Bolsista CNPq.

${ }^{3}$ Prof. Doutor, Departamento de Engenharia Rural, UNESP - Jaboticabal, Bolsista CNPq.

${ }^{4}$ Eng ${ }^{\circ}$ Agrônomo, UNESP - Jaboticabal.

${ }^{5}$ Pós-graduando, Doutorado (Produção Vegetal), DER/UNESP - Jaboticabal, Bolsista CAPES.

${ }^{6}$ Pós-graduando, Doutorado (Ciência do Solo), DER/UNESP - Jaboticabal.

Recebido pelo Conselho Editorial em: 12-9-2006
}

Aprovado pelo Conselho Editorial em: 6-6-2007 
sendo que a compactação do solo pode influenciar em todos esses, afetando a planta durante seu ciclo de desenvolvimento (SANTOS, 2005).

Estão disponíveis no mercado diversas marcas e modelos de equipamentos agrícolas, sendo esses os modificadores das características do solo, a exemplo das semeadoras-adubadoras que aplicam certa compactação ao solo por meio das rodas compactadoras, podendo influenciar no desenvolvimento das plantas. A pressão aplicada sobre o solo pelas rodas compactadoras pode ou não ser benéfica para a semente, dependendo do nível de pressão, do desenho e tipo da roda, da umidade no solo e das condições climáticas entre o período de semeadura e emergência (CASSEL et al., 1978).

Segundo REIS (2001), o bom desempenho de uma semeadora-adubadora, quanto à precisão de semeadura, é afetado por erros de dosagem, deposição, profundidade e acondicionamento de sementes. O desempenho é dependente da interferência de todos os componentes da máquina e não somente do mecanismo dosador.

FURLANI et al. (2001), em estudos realizados com a cultura do milho semeado a 0,035; 0,055 e $0,075 \mathrm{~m}$ de profundidade, com quatro níveis de compactação sobre a semente $(0 ; 98 ; 196$ e 294 N), observaram que o tempo médio para a emergência das plântulas foi de quatro dias, e a resistência do solo à penetração aumentou com a utilização das maiores cargas e profundidades de semeadura.

Trabalhando com três profundidades de semeadura $(0,02 ; 0,04$ e $0,06 \mathrm{~m})$ e quatro níveis de compactação do solo (0; 98; 196 e 294 N), na cultura do feijão, SORDI (2000) concluiu que o índice de emergência das plântulas foi mais rápido nas menores profundidades de semeadura e que nessas também ocorreram as maiores alturas de plantas e o maior número de grãos por vagem. Já em relação ao índice de sobrevivência das plantas de feijão, o melhor resultado foi na maior compactação (294 N) sobre o solo, concluindo que não houve diferença de rendimento de grãos entre os tratamentos.

SANTOS (2001) estudou os efeitos de três profundidades de semeadura $(0,02 ; 0,03$ e $0,06 \mathrm{~m})$ associadas a quatro intensidades de compactação $(0 ; 98 ; 196$ e $294 \mathrm{~N})$ na cultura da soja e concluiu que o índice de sobrevivência das plantas foi superior nas menores compactações e na menor profundidade.

Supõe-se que as cargas e as profundidades de semeadura possam interferir no processo de germinação e emergência da soja. Nesse sentido, o objetivo do trabalho foi avaliar o efeito de quatro cargas verticais e três profundidades na fileira de semeadura para a cultura da soja, nos parâmetros do solo e da planta.

\section{MATERIAL E MÉTODOS}

O experimento foi conduzido na área experimental do Laboratório de Máquinas e Mecanização Agrícola da UNESP - Jaboticabal (SP), localizada nas coordenadas geodésicas: latitude $21^{\circ} 14$ 'S e longitude $48^{\circ} 16^{\prime} \mathrm{W}$, com altitude média de $560 \mathrm{~m}$, clima Cwa (subtropical), de acordo com a classificação de Köeppen, solo da área experimental Latossolo Vermelho eutroférrico, conforme o Sistema Brasileiro de Classificação de Solos (EMBRAPA, 1999).

O delineamento experimental adotado foi o de blocos ao acaso, em esquema fatorial $(4 \times 3)$, sendo quatro níveis de carga vertical do solo sobre a fileira de semeadura (C0 - 0; C1 - 98; C2 - 196 e C3 - $294 \mathrm{~N})$ e três profundidades de semeadura (P3 - 0,03; P5 - 0,05 e P7 - 0,07 m), com três repetições, totalizando 36 observações.

O trabalho foi instalado em pista de ensaio, constituída de duas faixas de solo delimitadas por trilhos, medindo $1,50 \mathrm{~m}$ de largura por $22 \mathrm{~m}$ de comprimento cada uma e dispostas na direção leste-oeste. Sobre os trilhos, desloca-se um trole ao qual é possível acoplar acessórios, como plaina niveladora, sulcador, equipamentos para irrigação e roda compactadora. 
O preparo do solo foi efetuado um dia antes da instalação do ensaio com um trator de rabiça, ocasião em que se incorporou adubo ao solo na quantidade de $200 \mathrm{~kg} \mathrm{ha}^{-1}$ da formulação 0-20-20. Após essa operação, efetuaram-se o rastelamento e, posteriormente, o nivelamento com auxílio da plaina acoplada ao trole. O sulcador para a semente acoplado ao trole possuía régua graduada em milímetros para controle de profundidade de abertura de sulco que, de acordo com os tratamentos, foram de 0,03; 0,05 e 0,07 m. Após a abertura dos sulcos, depositaram-se manualmente as sementes distanciadas de $0,045 \mathrm{~m}$ (22,5 sementes por metro) e, em seguida, cobriram-se os sulcos, manualmente, com o auxílio de uma régua de madeira. Cada parcela experimental possuía $3,75 \mathrm{~m}^{2}$ $(1,50 \times 2,50 \mathrm{~m})$, com intervalo entre as mesmas de $1 \mathrm{~m}$.

A compactação do solo sobre a fileira de semeadura foi realizada após o fechamento dos sulcos, utilizando roda compactadora de alumínio com $0,40 \mathrm{~m}$ de diâmetro e 0,10 m de largura. Para obter as cargas, foram acrescentados sobre a plataforma de suporte da roda lastros de chumbo com massa individual de 9,8 kg. Foi aplicada irrigação suplementar com lâmina de água de $10 \mathrm{~mm}$ diários.



(a)

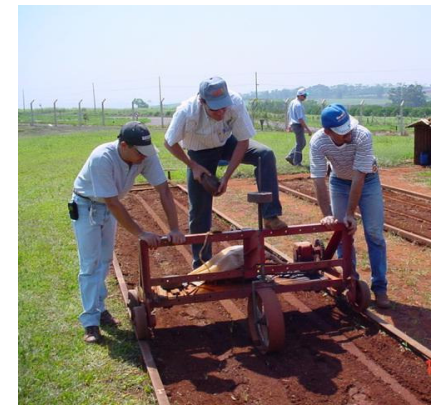

(b)



(c)

FIGURA 1. Vista da roda compactadora e dos lastros de chumbo responsáveis pela compactação do solo sobre a semente (a); execução da compactação do solo sobre as linhas de semeadura (b), e linhas de semeadura compactadas (c).

O número de dias para emergência foi obtido por contagens sucessivas até a estabilização do número de plantas na parcela toda, sendo os dados submetidos à formula de EDMOND \& DRAPALA (1958).

Para avaliar os perfis do solo, utilizou-se de perfilômetro com varetas espaçadas de 0,01 m, sendo cada uma delas graduada em $\mathrm{mm}$. O perfil do solo foi avaliado após o seu preparo e nivelamento, depois da abertura dos sulcos e, por fim, ao final do seu fechamento, a fim de determinar a área mobilizada do solo. A umidade do solo no momento do ensaio era de $17 \%$, avaliada pelo método gravimétrico (EMBRAPA, 1979).

A contagem do estande inicial foi realizada dez dias após a semeadura, data na qual todas as plântulas já haviam emergido, e a contagem do estande final realizada antes da colheita; com esses dados, calculou-se o índice de sobrevivência das plantas, dividindo a população inicial pela população final das plantas, multiplicado por 100.

Para a obtenção do rendimento de grãos, foi obtida a massa de grãos de todas as plantas em $1 \mathrm{~m}$ de cada parcela, sendo os resultados transformados em $\mathrm{kg} \mathrm{ha}^{-1}$.

Os dados obtidos foram submetidos à analise de variância e ao teste de comparação de médias de Tukey, a 5\% de probabilidade.

\section{RESULTADOS E DISCUSSÃO}

O número de dias para emergência de plântulas não apresentou resultados significativos em relação aos diferentes tratamentos, apresentando média de seis dias, resultado semelhante ao encontrado por FURLANI et al. (2001). 
Os estandes inicial e final não apresentaram resultados significativos, conforme pode ser observado pela Tabela 1, resultando em médias de 358 mil e 279 mil plantas por hectare, respectivamente. COELHO (1979) observou que a compressão do solo e a profundidade de semeadura pouco influenciaram nas condições iniciais de germinação e emergência, propiciando adequado estande de plantas.

De acordo com a Tabela 1, o índice de sobrevivência de soja para os diferentes tratamentos não variou significativamente, apresentando média de $79 \%$. Vale ressaltar que, no início do experimento, houve ataque de pássaros sobre as plântulas, o que resultou em maior variação entre as parcelas. Segundo SORDI (2000), a maior compactação do solo sobre a semente resultou em maior índice de sobrevivência de plantas, o que contradiz os resultados observados neste experimento. Uma possível explicação para isso pode ser o fato de que as condições físicas do solo com compactação zero possam ter apresentado melhores condições de porosidade, tendo a aeração mantida em melhores níveis que as demais, porém o fato de o experimento receber irrigação suplementar impede afirmar com maior certeza o ocorrido. Outra possibilidade para o fato pode ser o impedimento físico imposto pelo solo às raízes das plantas, evitando-as de explorar maior área de solo, dificultando acesso ao fertilizante empregado.

TABELA 1. Análise estatística do estande inicial, estande final e índice de sobrevivência das plantas.

\begin{tabular}{cccc}
\hline Fator & $\begin{array}{c}\text { Estande Inicial } \\
\left(1.000 \text { plantas ha }^{-1}\right)\end{array}$ & $\begin{array}{c}\text { Estande Final } \\
\left(1.000 \text { plantas ha }^{-1}\right)\end{array}$ & $\begin{array}{c}\text { Índice de Sobrevivência } \\
(\%)\end{array}$ \\
\hline Compactação (C) & $382,2 \mathrm{a}$ & $326,7 \mathrm{a}$ & $85 \mathrm{a}$ \\
C0 & $371,1 \mathrm{a}$ & $273,3 \mathrm{a}$ & $74 \mathrm{a}$ \\
C1 & $346,7 \mathrm{a}$ & $260,0 \mathrm{a}$ & $75 \mathrm{a}$ \\
C2 & $333,3 \mathrm{a}$ & $255,5 \mathrm{a}$ & $77 \mathrm{a}$ \\
C3 & $335 \mathrm{a}$ & & $80 \mathrm{a}$ \\
Profundidade (P) & $352 \mathrm{a}$ & $266,7 \mathrm{a}$ & $76 \mathrm{a}$ \\
P3 & $388 \mathrm{a}$ & $266,7 \mathrm{a}$ & $78 \mathrm{a}$ \\
P7 & & $303,3 \mathrm{a}$ & $1,58^{\mathrm{NS}}$ \\
Teste F & $0,55^{\mathrm{NS}}$ & & $0,144^{\mathrm{NS}}$ \\
C & $1,09^{\mathrm{NS}}$ & $1,57^{\mathrm{NS}}$ & $0,76^{\mathrm{NS}}$ \\
P & $1,09^{\mathrm{NS}}$ & $0,87^{\mathrm{NS}}$ & 53,4 \\
\hline C.V.\% & 25,3 & $1,07^{\mathrm{NS}}$ & 28,1 \\
\hline
\end{tabular}

Em cada coluna, para cada fator, médias seguidas de mesmas letras maiúsculas não diferem entre si, pelo teste de Tukey, a $5 \%$ de probabilidade. ${ }^{\text {NS}}$ : não-significativo $(\mathrm{P} \geq 0,05)$. C.V.: coeficiente de variação.

Conforme a Tabela 2, os resultados foram significativos para a área mobilizada pela haste sulcadora de abertura dos sulcos de semeadura, sendo quanto maior a profundidade, maior a área, apresentando valores de 21,5 a 71,6 $\mathrm{m}^{2}$ devido à remoção de maior quantidade de solo do sulco de semeadura das maiores para as menores profundidades de trabalho, concordando com os resultados de ALVES (2006). Com relação à compactação, os resultados não diferiram entre si, apresentando $0,47 \mathrm{~m}^{2}$ de média. De acordo com esses resultados, qualquer uma das cargas utilizadas para a compactação do solo sobre a semente poderia ser utilizada, pois a sua profundidade não seria influenciada. SANTOS (2005), ao analisar a área mobilizada na semeadura, nas profundidades de 0,03; 0,05 e $0,07 \mathrm{~m}$, observou seu aumento com o incremento da profundidade, o que também ocorreu neste experimento. 
TABELA 2. Análise estatística para área mobilizada e rendimento de grãos.

\begin{tabular}{ccc}
\hline Fator & $\begin{array}{c}\text { Área Mobilizada } \\
\left(\mathrm{cm}^{2}\right)\end{array}$ & $\begin{array}{c}\text { Rendimento de Grãos } \\
\left(\mathrm{kg} \mathrm{ha}^{-1}\right)\end{array}$ \\
\hline Compactação $(\mathrm{C})$ & $49 \mathrm{a}$ & $4.226 \mathrm{a}$ \\
C0 & $49 \mathrm{a}$ & $3.927 \mathrm{a}$ \\
C1 & $45 \mathrm{a}$ & $3.802 \mathrm{a}$ \\
C3 & $45 \mathrm{a}$ & $3.762 \mathrm{a}$ \\
\hline Profundidade $(\mathrm{P})$ & $22 \mathrm{a}$ & $4.176 \mathrm{a}$ \\
P3 & $47 \mathrm{~b}$ & $3.443 \mathrm{a}$ \\
P5 & $72 \mathrm{c}$ & $4.168 \mathrm{a}$ \\
P7 & $0,73^{\mathrm{NS}}$ & \\
TESTE F & $109,59^{* *}$ & $0,59^{\mathrm{NS}}$ \\
C & $0,93^{\mathrm{NS}}$ & $3,19^{\mathrm{NS}}$ \\
P x P & 17,7 & $0,95^{\mathrm{NS}}$ \\
\hline C.V.\% & 20,1 \\
\hline
\end{tabular}

Em cada coluna, para cada fator, médias seguidas de mesmas letras maiúsculas não diferem entre si, pelo teste de Tukey, a $5 \%$ de probabilidade. ${ }^{\mathrm{Ns}}$ : não-significativo $(\mathrm{P} \geq 0,05)$, **: significativo $(\mathrm{P} \leq 0,01)$; C.V.: coeficiente de variação.

Com relação ao rendimento de grãos, os resultados foram não-significativos, como indicado na Tabela 2, tanto em função da profundidade de semeadura quanto em relação à compactação aplicada no solo sobre as sementes pela roda compactadora com os diferentes lastros, apresentando, em média, rendimento de $3.930 \mathrm{~kg} \mathrm{ha}^{-1}$, porém, uma possível tendência de diminuição de rendimento com o aumento da compactação se faz presente, concordando com SALLES (1980), que, ao analisar o efeito da compactação sobre o rendimento da soja, observou que as maiores compactações restringiram a produção a $2.000 \mathrm{~kg} \mathrm{ha}^{-1}$. Tal fato deve-se, possivelmente, às restrições impostas pela compactação do solo à aeração, limitação do crescimento radicular e, como conseqüência, menor área de exploração de água e nutrientes.

\section{CONCLUSÕES}

A emergência, estandes inicial e final, índice de sobrevivência de plantas e rendimento de grãos não foram influenciados pela profundidade de semeadura e pela carga vertical aplicada sobre a fileira de semeadura, contrariando a hipótese proposta.

A área mobilizada diferiu em relação ao fator profundidade de semeadura, indicando que esse é proporcional à profundidade da haste sulcadora, concordando com a hipótese proposta.

\section{REFERÊNCIAS}

ALVES, P.J. Milho para silagem: produção em função da profundidade de semeadura e compressão do solo. 2006. 52 f. Monografia (Trabalho de Graduação em Zootecnia) - Faculdade de Ciências Agrárias e Veterinárias, Universidade Estadual Paulista, Jaboticabal, 2006.

CASSEL, P.K.; BOWEN, H.D.; NELSON, L.A. An evolution of mechanical impedance of three tillage treatments on Norfolk Loamy Sand. Soil Science of America Journal, Madison, v.42, n.1, p.116-20, 1978.

COELHO, F.C. Influência da profundidade de semeadura e compressão do solo, na emergência e desenvolvimento inicial da soja (Glycine max (L.) Merril) Cultivar UFV - 1. 1979. $81 \mathrm{f}$.

Monografia (Trabalho de Graduação em Agronomia) - Faculdade de Ciências Agrárias e Veterinárias, Universidade Estadual Paulista, Jaboticabal, 1979. 
EDMOND, J.B.; DRAPALA, W.L. The effects of temperature, sand and soil acetone on germination of okra seed. Proceedings of American Society Horticulture Science, Alexandria, v.71, p.428-34, 1958.

EMBRAPA - EMPRESA BRASILEIRA DE PESQUISA AGROPECUÁRIA. Serviço Nacional de levantamento e conservação do solo. Manual de métodos e análise de solo. Rio de Janeiro, 1979. "não pag.".

EMBRAPA - EMPRESA BRASILEIRA DE PESQUISA AGROPECUÁRIA. Sistema brasileiro de classificação de solos. Rio de Janeiro, 1999. 412 p.

FURLANI, C.E.A.; LOPES, A.; REZENDE, L.C.; SILVA, S.S.S.; LEITE, M.A.S. Influência da compactação do solo na emergência das plântulas de milho a diferentes profundidades de semeadura. Engenharia na Agricultura, Viçosa, v.9, n.3, p.147-53, 2001.

REIS, A.V. Erros na semeadura. Cultivar Máquinas, Pelotas, n.2, p.12-13, 2001.

SALLES, H.C. Influência da compactação do solo no desenvolvimento da soja (Glycine max (L.) Merril). 1980. 55 f. Monografia (Trabalho de Graduação em Agronomia) - Faculdade de Ciências Agrárias e Veterinárias, Universidade Estadual Paulista, Jaboticabal, 1980.

SANTOS, L.C. Emergência e desenvolvimento da cultura da soja (Glycine max L.) em função da profundidade de semeadura e da compactação do solo. 2005. 35 f. Monografia (Trabalho de Graduação em Agronomia) - Faculdade de Ciências Agrárias e Veterinárias, Universidade Estadual Paulista, Jaboticabal, 2005.

SANTOS, T.H.B. Emergência e desenvolvimento da cultura da soja (Glycine max L.) em função da profundidade de semeadura e compactação do solo sobre a semente. $2001.57 \mathrm{f}$. Monografia (Trabalho de Graduação em Agronomia) - Faculdade de Ciências Agrárias e Veterinárias, Universidade Estadual Paulista, Jaboticabal, 2001.

SORDI, F. Efeito da profundidade de semeadura e compactação do solo sobre a semente na cultura do feijoeiro (Phaseolus vulgaris). 2000. 50 f. Monografia (Trabalho de Graduação em Agronomia) - Faculdade de Ciências Agrárias e Veterinárias, Universidade Estadual Paulista, Jaboticabal, 2000. 